\title{
SOCIOCULTURAL PERCEPTION AND LIVING CONDITIONS OF FOREIGN CITIZENS IN STALINGRAD IN THE 1920s $-1930 \mathrm{~s}^{1}$
}

\author{
Taisiya V. Yudina \\ Volgograd State University, Volgograd, Russian Federation
}

\begin{abstract}
Introduction. In the late 1920s Stalingrad was undergoing major industrial construction and reconstruction. Due to the shortage of local labor resources, foreign labor resources were required. The study highlights the nationality and number of the labor force, arrival dates and participation in the city's public life. Methods and materials. The study used sources from the State Archive of Volgograd Oblast. The Research is based on comparative-historical and descriptive-historical methods. Analysis. Housing was the main issue in Stalingrad. Foreign specialists (Americans, Germans, Austrians, Czechs, Swedes) and their families were provided with housing, but living conditions were harsh. Moreover, despite the fact that salary of foreign labors was higher than salary of locals, foreign specialists still considered it insufficient. Providing foreign specialists with better living conditions, special product delivery and essential goods irritated the locals, whose standard of living was low. Results. Construction of buildings for foreign specialists began in the late 1920s. For local workers of such plants as the Stalingradskiy traktornyy zavod (Stalingrad Tractor Plant), the Barrikady (Titan-Barrikady) and the Krasny Oktyabr construction began in 1933. This helped to improve the city's housing situation and increase the standard of living and the number of citizens. In 1933 Stalingrad became a major industrial center; by the end of the 1930s, it had become a city with a large population, including foreigners who stayed in Stalingrad, provided training for local specialists, adapted to an unfamiliar social life, and mastered the Russian language.

Key words: population, USSR, Stalingrad, foreign specialists, living conditions, social difficulties.

Citation. Yudina T.V. Sociocultural Perception and Living Conditions of Foreign Citizens in Stalingrad in the 1920s - 1930s. Vestnik Volgogradskogo gosudarstvennogo universiteta. Seriya 4. Istoriya. Regionovedenie. Mezhdunarodnye otnosheniya [Science Journal of Volgograd State University. History. Area Studies. International Relations], 2021, vol. 26, no. 4, pp. 117-124. (in Russian). DOI: https://doi.org/10.15688/jvolsu4.2021.4.10
\end{abstract}

\section{ИНОСТРАНЦЫ В СТАЛИНГРАДЕ В КОНЦЕ 1920-х - 1930-е ГГ.: УСЛОВИЯ ЖИЗНИ, ВОСПРИЯТИЕ НОВОЙ СОЦИОКУЛЬТУРНОЙ СРЕДЫ ${ }^{1}$}

\section{Таисия Васильевна Юдина}

Волгоградский государственный университет, г. Волгоград, Российская Федерация

\begin{abstract}
Аннотация. С конца 1920-х гг. в Сталинграде развернулось масштабное промышленное строительство и реконструкция. Трудовых ресурсов оказалось недостаточно для создания индустриальной базы в городе. Необходимость привлечения иностранных специалистов для становления советской промышленности была очевидной. В статье освещаются сроки прибытия иностранцев в Сталинград, их национальность, численность, участие в общественной жизни города. Самой острой проблемой для сталинградского населения являлась жилищная. Вновь прибывающим иностранным специалистам и их семьям (американцам, немцам, австрийцам, чехам, шведам) жилье предоставлялось, но с первых дней приезда они оказались в чрезвычайно сложных бытовых условиях. Бытовые трудности иностранных работников дополнялись их недовольством размером заработной платы. Уровень зарплаты иностранцев на промышленных предприятиях Сталинграда был выше, чем отечественных специалистов и рабочих, но приглашенные специалисты из-за рубежа считали (2) его недостаточным. Предоставление иностранным специалистам лучших бытовых условий, спецснабжения
\end{abstract}


продуктами и товарами первой необходимости вызывало раздражение у сталинградцев, уровень жизни которых был невысок. С конца 1920-х гг. в Сталинграде приступили к строительству домов для иностранцев, с 1933 г. развернулось активное жилищное строительство для рабочих крупных предприятий Сталинградского тракторного завода, «Баррикад», «Красного Октября» и др., позволившее ослабить остроту жилищной проблемы городского населения. Продолжавшееся строительство жилья способствовало улучшению жизни горожан, их количественному росту. К 1933 г. Сталинград стал крупнейшим индустриальным центром Поволжья, к концу 1930-х гг. - городом с увеличивающимся населением, часть которого составили иностранцы, не уехавшие на родину, передававшие свои знания и опыт на производстве, адаптировавшиеся к непривычной общественной жизни, изучившие русский язык.

Ключевые слова: население, СССР, Сталинград, иностранные специалисты, жилищные условия, социально-бытовые трудности.

Цитирование. Юдина Т. В. Иностранцы в Сталинграде в конце 1920-х - 1930-е гг.: условия жизни, восприятие новой социокультурной среды // Вестник Волгоградского государственного университета. Серия 4, История. Регионоведение. Международные отношения. - 2021. - Т. 26, № 4. - С. 117-124. - DOI: https:// doi.org/10.15688/jvolsu4.2021.4.10

Введение. Процесс индустриализации, начавшийся в СССР в конце 1920-х, стал осуществляться при активном применении западных технологий и привлечении трудовых ресурсов [4]. Одним из основных городов сосредоточения иностранных специалистов в Советском Союзе был Сталинград. Прибывающие иностранцы трудоустраивались на промышленные объекты города, расселялись со своими семьями в дома, специально выстроенные для них.

В работе Н.А. Насоновой рассматриваются вопросы участия иностранных специалистов в индустриализации региона, передачи их производственного опыта сталинградским рабочим [7]. Проблемы социальной, культурной, бытовой адаптации иностранцев, условия их жизни освещаются в исследовании О.О. Резаненко [15]. Несмотря на проявленный интерес Н.А. Насоновой и О.О. Резаненко к теме, работа по комплексному и детальному изучению условий труда и проживания иностранных специалистов и их семей в Сталинграде, их взаимоотношений со сталинградцами требует дальнейшего исследования. Благодаря вновь выявленным архивным документам автор настоящего труда более подробно рассматривает социально-бытовые трудности, с которыми столкнулись иностранные специалисты и их семьи, приехавшие в Сталинград, взаимоотношения с административно-техническим персоналом заводов. Цель статьи - выяснить условия жизни иностранцев в Сталинграде, проследить их взаимоотношения в трудовых коллективах промышленных предприятий. Это позволит лучше разоб- раться в том, как иностранцы восприняли советскую действительность, какие усилия предпринимали местные органы власти по созданию комфортных условий труда и быта для них и отечественных работников, развитию Сталинграда с увеличивающимся населением в 1930-е годы.

Методы и материалы. В работе анализируются посвященные указанной теме неопубликованные источники, хранящиеся в Государственном архиве Волгоградской области в фондах Сталинградского окружного отдела труда Нижне-Волжского края (Ф. Р-315), отдела труда Нижне-Волжского крайисполкома (Ф. Р-509). В сведениях, протоколах, резолюциях, актах содержатся статистические материалы по численности иностранных специалистов, их условиям проживания, оплате труда и т. п. Докладные записки ОГПУ в окружной отдел труда заслуживают особого внимания. В источниках представлена информация об острых проблемах сталинградцев в вопросах условий и оплаты труда, жилищных условий. В данной работе при изучении источников применялись историко-сравнительный, историко-описательный методы.

Анализ. Значительные изменения в социально-экономической жизни города Сталинграда стали наблюдаться в связи с осуществлением в СССР процесса индустриализации с середины 1920-х годов.

К концу 1920-х гг. начавшиеся в Сталинграде крупномасштабные промышленные реконструкция и строительство обусловили приток рабочей силы из других регионов страны и из-за рубежа, что привело в 1930-е гг. к рос- 
ту численности городского населения. Численность рабочих, соответственно населению Сталинграда, пополнялась сельскими жителями из Сталинградской и близлежащих губерний. За 1926/27 г. в Сталинград прибыло 6000 деревенских жителей [6, с. 9]. В последующие годы большую работу по привлечению рабочей силы из близлежащих к Сталинграду волостей (Черного Яра, Каменного Яра, Капустина Яра, Владимирской и Астраханской губерний) на промышленные предприятия города проводили сотрудники Сталинградского окружного отдела труда [9].

Население Сталинграда было представлено коренным городским составом, сельскими жителями, прибывавшими из разных регионов страны на стройки и реконструкцию промышленных предприятий, а также иностранными специалистами со своими семьями, приехавшими в СССР в годы мирового экономического кризиса и участвовавшими в становлении советской промышленности на сталинградских предприятиях.

Иностранные специалисты - американцы, немцы, австрийцы, чехи, шведы - стали прибывать в Сталинград в конце 1920-х - начале 1930-х годов. Преобладающими среди них являлись американцы, трудившиеся на Сталинградском тракторном заводе, строительство которого осуществлялось по американским проекту и технологиям.

В конце 1920-х - начале 1930-х гг. Сталинград стал одним из крупнейших центров концентрации иностранных специалистов в Советском Союзе. В этом регионе развернулось масштабное промышленное строительство и реконструкция. Новая отрасль - тракторная (Сталинградский тракторный завод) создавалась на основе западных технологий и с широким использованием иностранного опыта. Для реконструкции заводов «Красный Октябрь» и «Баррикады» (базисных предприятий тракторного завода) из Европы и США поступало современное промышленное оборудование - станочное, металлургическое, электротехническое, а также прибывали квалифицированные кадры для наладки технологического процесса.

Строительство Сталинградского тракторного завода (СТ3) было крупнейшим промышленным проектом первой пятилетки. Зак- ладка СТЗ состоялась 12 июля 1926 г. по проекту специалистов Гипромеза без привлечения иностранцев. Однако в 1928 г. группа советских инженеров была командирована в США для изучения организации тракторостроения с целью проектирования завода на основе использования новейших технических достижений [15, с. 64].

По проекту компании Альберта Кана завод был изготовлен в США, затем демонтирован, под контролем американских специалистов - перевезен и собран в Советском Союзе, Сталинграде. В его монтаже участвовали около 80 машиностроительных компаний из США и несколько фирм из Германии. В начале июля 1929 г. на Тракторострой прибыла первая группа инженеров фирмы А. Кана, весной 1930 г. - группы иностранцев, заключивших индивидуальные контракты [15, с. 66-67].

Точную динамику количества иностранных специалистов, прибывших на промышленные предприятия Сталинграда, установить сложно. В 1931 г. на предприятиях Сталинграда общее количество иностранных работников составляло более 300 человек. В янваpe 1932 г. картина численности работавших иностранцев на трех крупнейших предприятиях Сталинграда была следующей: на «Баррикадах» - 188 человек, «Красном Октябре» 30 и СТ3 - 300 человек [5, л. 1], то есть более 500 человек.

С первых дней своего нахождения в городе иностранные специалисты оказались в новой социокультурной среде, в чрезвычайно сложных для них условиях. Так, прибывшим в декабре 1931 г. на завод «Баррикады» иностранцам предоставили квартиры, не соответствующие элементарным требованиям жилья: «в доме иностранцев на Волге страшнейший холод, отсутствие дров в силу не подвозки их» коммунальным отделом; 20 иностранцев расселили в квартиры без света, столов, стульев, вешалок и ключей от комнат. Не хватало кроватей, одеял (2 одеяла на 3 человека). Семьи иностранцев вынуждены были выселяться из таких квартир и переселяться к другим, имевшим элементарные удобства. Например, к трем неженатым мужчинам в 15-метровую комнату переселились муж с женой [11, л. 10].

Коммунальный отдел, занимавшийся вопросами снабжения необходимым инвента- 
рем квартир, и администрация завода «Баррикады» не предпринимали должных усилий по разрешению критической ситуации. Дом, построенный Баррикадстроем для иностранцев в октябре 1931 г., не был сдан из-за неработавших водопровода и канализации, но с начала ноября его стали заселять. Уже в феврале 1932 г. на «Баррикадах» насчитывалось 138 иностранных рабочих и служащих и 300 человек - членов их семей $[8$, л. 26].

Глубокое удивление иностранцев, членов их семей и возмущение представителей власти вызывали халатность и небрежное отношение к работе заводских сотрудников. Постоянные обращения иностранных граждан, например механика 4-го цеха завода «Баррикады» Гобнера к заведующему коммунальным отделом Линькову и его заместителю Потапенко с просьбой о подвозке ему дров и угля (8 раз (!) обращался), не выполнялись [11, л. 10], не обеспечивались топливом и другие жильцы дома для иностранцев. В заселенных квартирах иностранцев необходимая уборка производилась нерегулярно, комнаты холостяков не убирались уборщицами по два дня [11, л. 11].

Показательные в этом отношении выводы были сделаны представителями ВКП(б) и бригады Сталинградской городской рабочекрестьянской инспекции. По результатам обследований условий труда и быта иностранных специалистов на промышленных предприятиях Сталинграда и конкретным внесенным предложениям решением президиума Сталинградской городской расценочно-конфликтной комиссии был снят с работы с привлечением к уголовной ответственности заведующий коммунальным отделом завода «Баррикады» Линьков, а его заместителю Потапенко объявлен выговор, объявлен выговор и уволена с работы комендант общежития Юркина. Особым решением предлагалось обратиться в прокуратуру и привлечь к уголовной ответственности заведующего водопроводным цехом «Баррикады» за недопустимую оттяжку пуска водопровода по неуважительным причинам и виновных по строительству канализации и ее неисправности [5, л. 1-2].

Не хватало жилья вновь прибывающим отечественным специалистам и рабочим. Одни расселялись в не приспособленные для жилья помещения - сараи, подвалы, другие строили без разрешения дома вдоль берега реки Волги. К пополнению городского сталинградского населения так называемыми принудчиками, необходимой отечественной рабочей силой на промышленных предприятих, краевые и городские власти в полном объеме готовы не были. Неудовлетворительное выполнение программ по жилищному строительству для советских граждан, прибывавших на Сталинградский тракторный завод, отмечалось на закрытом заседании строительной комиссии в июне 1933 года. Из 16,5 млн руб., выделенных на жилищное строительство центром в 1933 г., за 1-е полугодие было освоено только 3 млн рублей. Ранее, в 1932 г., на строительство жилья было направлено 27,9 млн руб., и в этом же году началось строительство 14 домов для работников СТЗ и их семей, стали увеличиваться жилищные фонды других крупных предприятий Сталинграда.

В 1933 г. для выполнения намеченных планов по развитию СТ3 - крупнейшего промышленного проекта региона - предполагалось использовать незаселенные барачные постройки на других соседних стройках, приступить к строительству новых 20 домов и обсудить с краевым советом профсоюзов вопрос об удлинении рабочего дня до 10 (!) часов [13, л. 53]. Не только предложение об увеличении продолжительности рабочего дня (разрешение на работы в размере двух дополнительных часов в сутки было предоставлено) свидетельствовало об ухудшении условий труда работников Тракторостроя, но и состояние производственных помещений. Заводская электромастерская не отапливалась, отсутствовали стекла на окнах и столы для приема пищи (электрики обедали на полу и верстаках), не было горячей воды. Сталинградцы проявляли недовольство и настаивали на соблюдении требований по вопросам охраны труда [10], предоставления жилья. В начале 1930-х гг. необеспеченность рабочих жилплощадью отмечалась на всех предприятиях города. К концу 1939 г. в связи с значительным увеличением общего жилого фонда Сталинграда жилищные условия горожан улучшились.

Обратимся вновь к иностранным гражданам: к бытовой неустроенности добавлялось 
их недовольство оплатой труда. Иностранные специалисты, передавая свой производственный опыт и знания, стремились своевременно и качественно выполнить работу, но у них создавалось мнение, что их обманывают, «хотят изжить», например удерживали 76 руб. за перевозку семьи с холостяков. Или иностранный специалист 6-го разряда выполнял работу по 7-му разряду, а ему дополнительные выплаты не осуществляли. На сдельных работах в инструментальном цеху «Баррикад» при выполнении одних и тех же норм и заданий (обработки деталей) русский рабочий (по 8-му разряду) получал 47 руб., иностранный - 31 руб. 92 коп. (по 7-му разряду) и 22 руб. 80 коп. (по 6-му разряду). Несмотря на разные способы обработки деталей, квалификацию советских и иностранных рабочих, у последних такая оплата труда вызывала «неудовлетворительную реакцию». Иностранцы полагали, что такое отношение означает «протекцию русским» и требовали направления этого дела в прокуратуру [8, л. 27]. В то же время члены комиссии, проводившие обследование условий труда и быта рабочих на «Красном Октябре», утверждали, что иностранцы получают на 100 рублей больше, чем отечественные специалисты той же квалификации. Сталинградцы «частично, скрыто от иностранцев, проявляли обиду на неодинаковую оплату», доказывая, что некоторые советские работники более опытны, чем западные инженеры [1, л. 46].

Снижение реальных заработков иностранных специалистов стало наблюдаться с 1 апреля 1932 г., когда им прекратили оплачивать 25-процентную надбавку к окладу за отсутствие знаний по русскому языку. Проверяющими комиссиями отмечались случаи неоплаты сверхурочных иностранным специалистам, недостаточное внимание к их многочисленным рационализаторским предложениям, направленным на стимулирование советского производства. Из 48 рационализаторских предложений на заводе «Красный Октябрь», поступивших от иностранцев (38 немцев, чехов и словаков трудилось на указанном заводе в январе 1932 г.), только половина - 24 - были реализованы, и экономия составила 182 тыс. рублей. Остальные предложения рассмотрены не были [8, л. 28].
С огромным энтузиазмом иностранные специалисты принимали участие не только в рационализации производства, но и в общественной жизни. 22 иностранца (по нашим подсчетам), работавшие на заводе «Баррикады» в начале 1932 г., были избраны: в Сталинградский городской совет - 1 чел., районный совет - 1 чел., заводской комитет -1 чел., заводское бюро инженерно-технической службы - 1 чел., бюро рабочего изобретательства - 1 чел. и т. д. [8, л. 28].

Работая, участвуя в общественной жизни трудового коллектива, сталинградских органов власти, иностранцы знакомились с иными представлениями о трудовой этике, производственной культуре, непривычной общественной жизни, открывали новый мир для себя. Западным рабочим с левыми взглядами рассказывали о Конституции СССР, предлагали вступать и принимали в ряды коммунистической партии. Несмотря на социальнобытовые трудности, способствовавшие отъезду иностранцев на родину, часть пополняла городское население и оставалась в СССР, Сталинграде. Среди них - те, кто подвергался ограничениям и ущемлениям на Западе, хотел получить в Советском Союзе образование, недоступное в родной стране [15, c. 135]. Они изучали русский язык, передавали свои знания и опыт на производстве, ближе знакомились с горожанами, получали советское гражданство.

На отдельных предприятиях, например на заводе «Сельмаш» (Саратов), где предоставлялись комфортные условия быта и труда иностранным специалистам, прибывшим по приглашению, и не тратилось много времени на обустройство, перенятие их производственного опыта и знаний советскими коллегами происходило значительно быстрее. Все специалисты (86 чел.) «Сельмаша» были обеспечены жильем в новом доме - доме иностранцев с 87 комнатами со всеми необходимыми инвентарем и коммунальными услугами [2, л. 40]. Иностранцам предоставлялась бесплатная медицинская помощь, было организовано снабжение продуктами и товарами из центрального магазина Саратова по нормам Народного комиссариата снабжения. На заводе работали столовая и буфет. На другом саратовском заводе имени Шеболдаева ино- 
странные специалисты оказались в сложных условиях, похожих на условия в Сталинграде [3, л. 42].

Несмотря на трудности, с которыми столкнулись иностранцы в России, современный исследователь О.О. Резаненко отмечает их привилегированное положение в социальнобытовых вопросах, оплате труда по отношению к советским работникам [15, с. 109], что создавало нездоровую обстановку в трудовых коллективах. На заводе «Баррикады» отмечались случаи недружелюбного, грубого и «несерьезного» отношения советских работников расчетного отдела, бухгалтерии, административно-технического персонала механического и инструментального цехов к иностранным специалистам [14, л. 6]. Это приводило к невыполнению производственных заданий, планов, в целом - к сложным взаимоотношениям между иностранцами и сталинградцами.

Принципы западной производственной культуры, которые пытались внедрять иностранные специалисты на промышленных предприятиях Сталинграда, не соблюдались в должной мере административно-техническим персоналом заводов. На «Баррикадах», где без спецодежды работать было невозможно, как иностранным специалистам, так и сталинградским рабочим она выдавалась несвоевременно и некачественной (детских размеров, из очень грубого материала). Не всех работников обеспечивали необходимой питьевой водой со льдом, а там, где она предоставлялась, отсутствовали кружки, крышки для баков; санитарное состояние цехов проверяющими Сталинградского губернского отдела труда было признано «безобразным» [12]. Многочисленные комиссии, работавшие на предприятиях Сталинграда, требовали немедленного устранения недостатков, выполнения обоснованных претензий иностранных специалистов и производственных планов, улучшения условий труда работников.

Крупное промышленное строительство и реконструкция с участием иностранных трудовых ресурсов, постоянный контроль и координация деятельности местных органов власти способствовали превращению Сталинграда в один из мощных индустриальных районов страны с увеличивающимся городским населением. В 1931 г. число жителей Сталин- града составляло около 300000 человек. В 1939 г., по данным Всесоюзной переписи, в городе проживало 445500 человек. Численность горожан за десятилетие увеличилось почти в 1,5 раза. В 1939 г. более 60 \% жилой площади для сталинградцев составляли каменные многоэтажные дома с коммунальными и бытовыми удобствами. Продолжалось строительство новых зданий. Успешно, начиная с 1933 г. была решена проблема развития рабочих поселков СТЗ, «Баррикад», «Красного Октября». Созидательную работу сталинградцев, их жизнь в начале 1940-х гг. нарушила Великая Отечественная война.

Результаты. Иностранным специалистам, прибывавшим в Сталинград для строительства и реконструкции промышленных предприятий, предоставлялось жилье в специально выстроенных для них домах, создавались определенные жилищно-бытовые условия в квартирах (тепло, электрическое освещение, необходимая мебель, уборка квартир и др.). Однако на тех предприятиях, например на заводе «Баррикады», где не предоставлялись жизненно важные условия для иностранцев, наблюдались их обоснованные претензии и недовольства. Бытовая неустроенность иностранных специалистов влияла на их производственную деятельность, отношения. Иностранцы жаловались на недостаточные оплату труда и внимание к их рационализаторским предложениям, несоблюдение производственной культуры, грубое отношение управленческого и технического персонала. Несмотря на бытовые и производственные трудности, иностранные специалисты, открывая новый мир для себя, передавали свои опыт и знания, активно участвовали в практике рационализации, общественной жизни предприятий, города, превращении Сталинграда в крупный индустриальный центр.

\section{ПРИМЕЧАНИЕ}

${ }^{1}$ Исследование выполнено при финансовой поддержке РФФИ и Администрации Волгоградской области в рамках научного проекта № 19-49340003 p а «Сталинградцы на переломе эпох (середина 1920-х - конец 1930-х гг.): социально-экономическое положение и культурная жизнь». 
The reported study was funded by RFBR and the government of Volgograd region according to the research project №19-49-340003 p_a "Stalingraders at the turning point of the era (mid-1920s - end of the 1930s): socio-economic situation and cultural life".

\section{СПИСОК ЛИТЕРАТУРЫ}

1. Акт от 3 мая 1931 г. по заводу «Красный Октябрь» // Государственный архив Волгоградской области (ГАВО). - Ф. Р-509. - Оп. 1. - Д. 3. - 3 л.

2. Выводы обследования о состоянии условий труда иностранных специалистов и рабочих на заводе Комбайнов // ГАВО. - Ф. Р-509. - Оп. 1. Д. 10. -2 л.

3. Выводы по обследованию иностранных рабочих при заводе имени Шеболдаева // ГАВО. Ф. Р-509. - Оп. 1. - Д. 10. - 2 л.

4. Гордин, А. А. Формирование представлений советских рабочих 30 -х годов о общественнополитической жизни в странах Запада (на материалах Горьковского автомобильного завода) : автореф. дис. ... канд. ист. наук (07.00.02) / Гордин Алексей Александрович. - Н. Новгород, 2004. - 27 c.

5. Доклад представителя ВКП (б) и бригады Сталинградской городской рабоче-крестьянской инспекции по итогам обследования использования иностранных специалистов по Сталинградской группе заводов // ГАВО. - Ф. Р-509. - Оп. 1. - Д. 10. - 3 л.

6. Луночкин, А. В. Сталинград накануне индустриализации: социально-культурное развитие и благоустройство / А. В. Луночкин, Е. Л. Фурман // Вестник Волгоградского государственного университета. Серия 4, История. Регионоведение. Международные отношения. - 2020. - Т. 25, № 3. - С. 6-20. DOI: https://doi.org/10.15688/jvolsu4.2020.3.1

7. Насонова, Н. А. Иностранные специалисты на предприятиях Сталинграда в 1930-е годы / Н. А. Насонова // Модернизация и традиции Нижнее Поволжье как перекресток культур : материалы Междунар. науч.-практ. конф., посвящ. 100-летию со дня рождения академика Д.С. Лихачева. - Волгоград : Изд-во ВолГУ, 2006. - С. 206-211.

8. Письмо в спецуправление НКТ СССР и РСФСР от Нижне-Волжского крайтруда от 28.01.1932 г. // ГАВО. - Ф. Р-509. - Оп. 1.-Д. 10. -4 л.

9. Письмо заведующего окружным отделом труда в окружной комитет ВКП(б) от 29.01.1929 г. // ГАВО. - Ф. Р-315. - Оп. 2. -Д. 10. - 1 л.

10. Письмо начальника окружного отдела ОГПУ в окружной отдел труда от 18.01.1929 г. // ГАВО. - Ф. Р-315. - Оп. 2. -Д. 10. - 1 л.

11. Проект постановления выездного объединенного заседания президиума городской контрольной комиссии и коллегии городской рабоче- крестьянской инспекции // ГАВО. - Ф. Р-509. Оп. 1. - Д. 10. -2 л.

12. Проект резолюции «О состоянии охраны труда и техники безопасности на заводе «Баррикады» // ГАВО. - Ф. Р-509. - Оп. 1. - Д. 15. - 1 л.

13. Протокол № 4а закрытого заседания строительной комиссии при президиуме Нижне-Волжского крайисполкома ог 21.06.1933 г. // ГАВО. -Ф. Р-509. Оп. 1. -Д. 14. -2 л.

14. Протокол заседания комиссии по обследованию условий труда иностранных рабочих на заводе «Баррикады», произведенным с 13 по 15 февраля 1932 г. // ГАВО. - Ф. Р-509. - Оп. 1. - Д. 13. - 2 л.

15. Резаненко, О. О. Иностранные специалисты на промышленных предприятиях Сталинграда в конце 1920-х - 1930-е гг. : дис. ... канд. ист. наук (07.00.02) / Резаненко Ольга Олеговна. - Волгоград, 2018. $-215 \mathrm{c}$.

\section{REFERENCES}

1. Akt ot 3 maia 1931 g. po zavodu «Krasnyi Oktiabr» [Act of May 3, 1931 on the Krasny Oktyabr Plant]. Gosudarstvennyy arkhiv Volgogradskoy oblasti (GAVO) [State Archive of Volgograd Region (GAVO)], f. R-509, op. 1, d. 3.31.

2. Vyvody obsledovaniia o sostoianii uslovii truda inostrannykh spetsialistov i rabochikh na zavode Kombainov [Inspection Conclusion of Working Conditions of Foreign Specialists and Workers at the Combine Factory]. GAVO, f. R-509, op. 1, d. 10. 21.

3. Vyvody po obsledovaniiu inostrannykh rabochikh pri zavode imeni Sheboldaeva [Inspection Conclusion of Foreign Workers at the Sheboldaev's Plant]. GAVO, f. R-509, op. 1, d. 10.21.

4. Gordin A.A. Formirovanie predstavlenii sovetskikh rabochikh 30-kh godov o obshchestvenno-politicheskoi zhizni v stranakh Zapada (na materialakh Gorkovskogo avtomobilnogo zavoda): avtoref. dis. ... kand. ist. nauk (07.00.02) [The Formation of Soviet Workers' Perceptions of Social and Political Life in the West in the 30s (On the Materials of the Gorkovsky Avtomobilny Zavod). Cand. hist. sci. abs. diss.]. Nizhnii Novgorod, 2004. 27 p.

5. Doklad predstavitelia VKP(b) i brigady Stalingradskoi gorodskoi raboche-krestianskoi inspektsii po itogam obsledovaniia ispolzovaniia inostrannykh spetsialistov po Stalingradskoi gruppe zavodov [Report of the Representative of the All-Union Communist Party (Bolsheviks) and the Stalingrad Workers' and Peasants' Inspectorate on the Results of the Survey of the Employment of Foreign Specialists in the Stalingrad Plant Group]. GAVO, f. R-509, op. 1, d. 10.31 . 


\section{РУСЬ, РОССИЙСКАЯ ИМПЕРИЯ И СССР}

6. Lunochkin A.V., Furman E.L. Stalingradnakanune industrializatsii: sotsial'no-kul'turnoe razvitie i blagoustroystvo [Stalingrad on the Eve of Industrialization: Social and Cultural Development and Improvement]. Vestnik Volgogradskogo gosudarstvennogo universiteta. Seriia 4, Istoriia. Regionovedenie. Mezhdunarodnye otnosheniia, 2020, vol. 25, no. 3, pp. 6-20. DOI: https:// doi.org/10.15688/jvolsu4.2020.3.1.

7. Nasonova N.A. Inostrannye spetsialisty na predpriiatiiakh Stalingrada v 1930-e gody [Foreign Specialists at Stalingrad Enterprises in the 1930s]. Modernizatsiia i traditsii - Nizhnee Povolzhe kak perekrestok kultur: materialy Mezhdunar. nauch.-prakt. konf., posviashch. 100-letiiu so dnia rozhdeniia akademika D.S. Likhacheva [Modernization and Traditions - The Lower Volga Region as a Crossroads of Cultures: Materials of the International Scientific and Practice Conference Dedicated to the $100^{\text {th }}$ Anniversary of Academician D.S. Likhachev]. Volgograd, Izd-vo VolGU, 2006,pp. 206-211.

8. Pismo v spetsupravlenie NKT SSSR i RSFSR ot Nizhne-Volzhskogo kraitruda ot 28.01.1932 g. [A Letter to the NKT USSR and RSFSR Special Management from the Lower Volga Region Kraitrud of January 28, 1932]. GAVO, f. R-509, op. 1, d. 10. 41.

9. Pismo zaveduiushchego okruzhnym otdelom truda v okruzhnoi komitet VKP(b) ot 29.01.1929 g. [A Letter from the District Labor Department Supervisor to the District Committee of the All-Union Communist Party (Bolsheviks) of January 29, 1929]. GAVO, f. R-315, op. 2, d. 10. 11.

10. Pismo nachalnika okruzhnogo otdela OGPU v okruzhnoi otdel truda ot 18.01.1929 g. [A Letter from the
OGPU District Department Head to the District Labor Department of January 18, 1929]. GAVO, f. R-315, op. 2, d. 10.11 .

11. Proekt postanovleniia vyezdnogo obieedinennogo zasedaniia prezidiuma gorodskoi kontrolnoi komissii i kollegii gorodskoi rabochekrestianskoi inspektsii [Draft Resolution of the Field Joint Meeting of the City Control Commission Presidium and the Board of the City Workers' and Peasants' Inspectorate]. GAVO, f. R-509, op. 1, d. 10. 21.

12. Proekt rezoliutsii «O sostoianii okhrany truda i tekhniki bezopasnosti na zavode «Barrikady» [Draft Resolution "On Protection of Labour Conditions at the Barrikady Plant"]. GAVO, f. R-509, op. 1, d. 15. 11.

13. Protokol № 4a zakrytogo zasedaniia stroitelnoi komissii pri prezidiume Nizhne-Volzhskogo kraiispolkoma ot 21.06.1933 g. [Report No. 4a of the Closed Meeting of the Construction Committee at the Presidium of the Nizhne-Volzhsky Krajispolkom of June 21, 1933]. GAVO, f. R-509, op. 1, d. 14. 21.

14. Protokol zasedaniia komissii po obsledovaniiu uslovii truda inostrannykh rabochikh na zavode «Barrikady», proizvedennym s 13 po 15 fevralia $1932 \mathrm{~g}$. [Report of the Committee Meeting for Inspecting the Working Conditions of Foreign Workers at the Barrikady Plant During February 13-15, 1932]. GAVO, f. R-509, op. 1, d. 13. 21.

15. Rezanenko O.O. Inostrannye spetsialisty na promyshlennykh predpriiatiiakh Stalingrada $v$ kontse 1920-kh-1930-e gg.: dis. ... kand. ist. nauk [Foreign Specialists at Manufacturing Corporations in the Late $1920 \mathrm{~s}-1930$ s. Cand. hist. sci. abs. diss.].Volgograd, 2018. 215 p.

\section{Information About the Author}

Taisiya V. Yudina, Doctor of Sciences (History), Professor, Department of Russian and World History, Archaeology, Volgograd State University, Prosp. Universitetsky, 100, 400062 Volgograd, Russian Federation, taisia.yudina@volsu.ru, https://orcid.org/0000-0003-0526-6484

\section{Информация об авторе}

Таисия Васильевна Юдина, доктор исторических наук, профессор кафедры отечественной и всеобщей истории, археологии, Волгоградский государственный университет, просп. Университетский, 100, 400062 г. Волгоград, Российская Федерация, taisia.yudina@volsu.ru, https://orcid.org/0000-0003-0526-6484 